\title{
PENGEMBANGAN MODEL PEMBELAJARAN \\ CONTEXTUAL TEACHING AND LEARNING \\ UNTUK MENINGKATKAN KREATIVITAS SISWA
}

\author{
Siti Fatmawati \\ Institut Agama Islam Syarifuddin Lumajang, Indonesia \\ Email: elyaqien54@gmail.com
}

\begin{abstract}
Abstrak
Model pembelajaran adalah salah satu syarat dalam meningkatkan pembelajaran siswa, baik dalam hal yang berkaitan dengan minat siswa di kelas, hingga kreatifitas siswa dalam mengikuti proses pembelajaran. Salah satu model pembelajaran yang lagi tren saat ini adalah contextual teaching and learning. Penelitin ini membahas bagaimana pengembangan model pembelajaran contextual teaching and learning di MIS Tarbiyatul Mubtadiin Labruk Lor Lumajang sehingga mampu meningkatkan kreativitas siswa. Penelitian ini merupakan penelitian lapangan (field study) dengan menggunakan pendekatan kualitatif deskriftif.

Hasil penelitian menunjukan pengembangan Model Pembelajaran contextual teaching and learning dilakukan dengan beberapa cara; pengembangan melalui Constructivisme, pengembangan melalui questioning, dan melalui Learning Community.
\end{abstract}

Kata kunci: Constructivisme, questioning, Learning Community.

\section{Pendahuluan}

Pendidkan tidak pernah terlepas dari proses pembelajaran, karena pada hakekatnya proses pembelajaran adalah untuk mengembangkan aktivitas dan kreativitas peserta didik, melalui berbagai interaksi dan berbagai pengalaman belajar. Keberhasilan guru dalam mengajar tak lepas dari strategi yang digunakan. Strategi pembelajaran merupakan suatu perencanaan yang berisi tentang rangkaian kegiatan yang didesain untuk mencapai tujuan pendidikan. Untuk itu tujuan pendidikan akan dapat tercapai jika strategi yang digunakan mampu diimplementasikan secara optimal. Salah satu aspek terciptanya strategi pembelajaran adalah tidak pernah terlepas dari tiga komponen penting yang saling terkait satu sama lain. Tiga komponen penting tersebut adalah: 1) Kurikulum, materi yang akan diajarkan; 2) Proses, bagaimana materi diajarkan; 3) Produk, hasil 
dari proses pembelajaran. ${ }^{1}$ Oleh sebab itu keberhasilan guru dalam mengajar salah satunya adalah tergantung pada strategi yang digunakan. Strategi pembelajaran merupakan suatu perencanaan yang berisi tentang rangkaian kegiatan yang didesain untuk mencapai tujuan pendidikan. Untuk itu tujuan pendidikan akan dapat tercapai jika strategi yang digunakan mampu diimplementasikan secara optimal.

Kurangnya kreatifitas guru dalam menggali metode yang biasa dipakai untuk pendidikan agama menyebabkan pelaksanaan pembelajaran cenderung monoton. Sistem pembelajaran lebih menitikberatkan pada aspek korespondensi tekstual yang lebih menekankan hafalan teks-teks. Cara seperti itu bisa membuat siswa, kurang bersemangat dalam belajar, bosan dan jenuh, sehingga menyebabkan rendahnya minat dan hasil belajar siswa di sekolah. ${ }^{2}$

Pada saat ini, banyak konsep-konsep pembelajaran yang tengah dikembangkan untuk menunjang keberhasilan pendidikan. Salah satu diantaranya adalah konsep pembelajaran berdasarkan pendekatan kontekstual. Pendekatan ini berfokus pada kegiatan guru untuk mengaitkan kegiatan pembelajaran yang dikembangkan dengan situasi nyata dalam belajar siswa. Permasalahan terbesar yang dihadapi para peserta didik sekarang adalah mereka belum bisa menghubungkan antara apa yang mereka pelajari dengan situasi dunia nyata dan bagaimana pengetahuan itu akan digunakan. Karena cara mereka memperoleh informasi dan motivasi diri belum tersentuh oleh metode yang betul-betul bisa membantu mereka. Di sisi lain, tentunya siswa menyadari bahwa apa yang mereka pelajari saat ini akan sangat berguna bagi kehidupan mereka di masa datang, yaitu saat mereka hidup bermasyarakat ataupun saat berada di tempat kerja kelak. ${ }^{3}$ Oleh karena itu diperlukan suatu metode

\footnotetext{
${ }^{1}$ Adi W. Gunawan, Genius Learning Strategy, (Jakarta: PT. Gramedia Pustaka Utama, 2002), 1

2Ramayulis, Metodologi Pendidikan Agama Islam, (Jakarta: Kalam Mulia, 2005), 30

${ }_{3}^{3}$ Muhibbin Syah, Psikologi Belajar, (Jakarta: PT Raja Grafindo Persada, 2009), 19
} 
yang benar-benar bisa memberi jawaban dari masalah ini. Salah satu metode yang bisa lebih memberdayakan siswa adalah pendekatan kontekstual (Contextual Teaching and Learning) yang biasa dikenal dengan sebutan (CTL). Contextual Teaching and Learning adalah sistem pembelajaran yang cocok dengan kinerja otak, untuk menyusun pola yang mewujudkan makna, dengan cara menghubungkan muatan akademis dengan konteks kehidupan sehari-hari peserta didik. Hal ini penting diterapkan agar informasi yang diterima tidak hanya disimpan dalam memori jangka pendek, yang mudah dilupakan, tetapi dapat disimpan dalam memori jangka panjang sehingga akan dihayati dan diterapkan dalam tugas pekerjaan. ${ }^{4}$

MIS Tarbiyatul Mubtadiin Labruk Lor Lumajang adalah salah satu lembaga pendidikan swasta yang sekarang sedang mengalami perkembangan yang signifikan, terutama dalam proses belajar mengajar. Sebelumnya lembaga ini terdapat siswa yang hasil belajarnya rendah, khususnya di kelas V. Kondisi tersebut bukan semata-mata karena daya serap siswa yang rendah karena siswa-siswi, terbukti memiliki kemampuan di atas rata-rata siswa-siswi sekolah lain; banyak faktor yang mempengaruhinya. diantaranya karena model pembelajaran yang kurang relevan, model pembelajaran yang kurang menarik, media pembelajaran yang kurang mendukung dan lain-lain. ${ }^{5}$

Dengan perkembangan yang semakin maju ini para guru berupaya untuk memperbaiki model yang telah dilakukan sebelumnya, terbukti pada sekarang ini banyak sekali peningkatan pembelajaran. Hal itu dilakukan dengan cara mengelola pembelajaran dengan model pembelajaran yang sesuai dengan kebutuhan siswa, salah satunya adalah model pembelajaran Contextual Teaching and Learning.

${ }^{4}$ Wina Sanjaya, Strategi Pembelajaran: Berorientasi Standar Proses Pendidika, (Jakarta: Kencana, 2008), 255

${ }^{5}$ Rachellia Putri, wawancara, , MIS Tarbiyatul Mubtadiin Labruk Lor Lumajang, 28 Februari 2018. 


\section{Pembahasan}

\section{Pengembangan Model Pembelajaran Contextual Teaching And Learning}

Madrasah Ibtidaiyah Tarbiyatul Mubtadiin ini didirikan pada tahun 1961 Oleh Tokoh-tokoh Ulama Desa Labruk Lor Kecamatan Lumajang, yang beralamatkan di jalan Letkol Slamet Wardoyo No. 86 Labruk Lor Kec./Kab. Lumajang Jawa Timur. ${ }^{6}$ Kehadiran MIS Tarbiyatul Mubtadiin Labruk Lor Lumajang tidak terlepas dari keinginan untuk mewujudkan sebuah lembaga pendidikan yang ingin memberikan kontribusi untuk pembangunan bangsa, negara dan agama. ${ }^{7}$

Berdasarkan hasil observasi peneliti bahwa pengembangan model pembelajaran contextual teaching and learning untuk meningkatkan kreativitas siswa pada mata pelajaran tematik kelas V di MIS Tarbiyatul Mubtadiin Labruk Lor Lumajang dilakukan dengan beberapa cara, diantaranya adalah model pembelajaran contextual teaching and learning melalui constructivisme, questioning dan melalui learning community. Tujuan dari pengembangan model pembelajaran contextual teaching and learning digunakan untuk memotivasi siswa untuk memahami makna materi pelajaran yang dipelajarinya dengan mengkaitkan materi tersebut dengan konteks kehidupan mereka sehari-hari sehingga siswa memiliki pengetahuan atau ketrampilan yang secara refleksi dapat diterapkan dari permasalahan kepermasalahan lainya. Agar dalam belajar itu tidak hanya sekedar menghafal tetapi perlu dengan adanya pemahaman. Model pembelajaran ini menekankan pada pengembangan minat pengalaman siswa. Untuk melatih siswa agar dapat berpikir kritis dan terampil dalam memproses pengetahuan agar dapat menemukan dan menciptakan sesuatu yang bermanfaat bagi dirinya sendiri dan orang lain. Agar pembelajaran lebih produktif dan bermakna. Untuk mengajak anak pada suatu aktivitas yang mengkaitkan materi akademik dengan konteks 
kehidupan sehari-hari. Agar siswa secara individu dapat menemukan dan mentrasfer informasi-informasi komplek dan siswa dapat menjadikan informasi itu miliknya sendiri. ${ }^{8}$

\section{Constructivisme}

Dalam meningkatkan kreativitas siswa pada mata pelajaran tematik kelas V di MIS Tarbiyatul Mubtadiin Labruk Lor Lumajang. Sebagaimana hasil observasi peneliti, bahwa model pembelajaran contextual teaching and learning melalui constructivisme untuk meningkatkan kreativitas siswa pada mata pelajaran tematik kelas V di MIS Tarbiyatul Mubtadiin Labruk Lor Lumajang adalah dilakukan dengan beberapa langkah, yaitu: 1) Kegiatan Awal. Guru menyiapkan peserta didik secara psikis dan fisik untuk mengikuti proses pembelajaran: a) Apersepsi, sebagai penggalian pengetahuan awal siswa terhadap materi yang akan diajarkan; b) Guru menyampaikan tujuan pembelajaran dan pokok-pokok materi yang akan dipelajari; c) Penjelasan tentang pembagian kelompok dan cara belajar; 2) Kegiatan Inti: a) Siswa bekerja dalam kelompok menyelesaikan permasalahan yang diajukan guru; b) Siswa diminta untuk menyampaikan pengalaman dari hasil kerja kelompok; c) Siswa dalam kelompok menyelesaikan lembar kerja yang diajukan guru. Guru berkeliling untuk mengamati, memotivasi, dan memfasilitasi kerja sama; d) Guru mengadakan refleksi dengan menanyakan kepada siswa tentang hal-hal yang dirasakan siswa, baik tentang pengalaman siswa, pengetahuan siswa dan materi yang belum dipahami dengan baik; 3) Kegiatan Akhir: a) Guru menyimpulkan materi pembelajaran dan memberikan; b) Guru bersama siswa menutup pembelajaran dengan berdoa bersama. ${ }^{9}$ Berdasarkan hasil observasi tersebut senada dengan yang disampaikan oleh kepala sekolah, guru kelas $\mathrm{V}$ dan siswa. Sebagaimana yang disampaikan oleh Rofi'ati selaku guru kelas V dalam

\footnotetext{
${ }^{8}$ Ismail, Strategi Pembelajaran Agama Islam Berbasis PAIKEM, (Semarang. Rasail Media Group, 2008), 45.

${ }^{9}$ Observasi, MIS Tarbiyatul Mubtadiin Labruk Lor Lumajang, 12 Februari 2018
} 
wawancaranya menyampaikan bahwa: "Dalam penerapan metode CTL ini dilakukan dengan beberapa langkah, yaitu tahap pertama siswa dipersiapkan secara psikis dan fisik untuk mengikuti proses pembelajaran, memberikan apresiasi dan menjelaskan tujuan pembelajaran, tahap kedua siswa dibentuk dalam 5 kelompok, masing masing kelompok ada yang 6 dan ada yang 7 siswa, kemudian setiap kelompok diminta utuk mempelajari sendiri LKS yang sudah disediakan, selajutnya siswa diminta untuk mempresetasikan, kemudian dilanjutkan dengan tanya jawab. Sedangkan kegiatan akhir adalah guru menyimpulkan dan meberikan tugas kepada siswa". ${ }^{10}$

\section{Questioning}

Pengembangan model pembelajaran Contextual Teaching and Learning melalui questioning untuk meningkatkan kreativitas siswa adalah merupakan strategi bertanya yang dilakukan guru untuk mendorong, membimbing dan menilai kemampuan berpikir siswa sedangkan bagi siswa kegiatan bertanya merupakan bagian penting dalam melaksanakan pembelajaran yang berbasis Inquiry. Dalam sebuah pembelajaran yang produktif, kegiatan bertanya berguna untuk Menggali informasi, baik administratif maupun akademis, mengecek pengetahuan awal siswa dan pemahaman siswa dan lain-lain. ${ }^{11}$ Menurut Dimyati, Bertanya (Questioning) merupakan kegiatan guru untuk mendorong, membimbing dan menilai kemampuan berpikir siswa. Sedangkan bagi siswa yang merupakan bagian penting dalam pembelajaran yang berbasis inquiry. ${ }^{12}$

Sedangkan model pembelajaran contextual teaching and learning melalui questioning untuk meningkatkan kreativitas siswa pada mata pelajaran tematik kelas V di MIS Tarbiyatul Mubtadiin Labruk Lor Lumajang dilakukan dengan beberapa tahap, yaitu: 1) Kegiatan Awal.

\footnotetext{
${ }^{10}$ Rofi'ati, wawancara, , MIS Tarbiyatul Mubtadiin Labruk Lor Lumajang, 12 Februari 2018

${ }^{11}$ WinaSanjaya, Strategi Pembelajaran: Berorientasi Standar Proses Pendidikan, (Jakarta: Kencana, 2008), 245.

${ }^{12}$ Dimyati dan Mudjiono, Belajar dan Pembelajaran, (Jakarta: PT Rineka Cipta, 2009), 15.
} 
Guru memberikan salam dan menanyakan kabar siswa, guru mengabsen siswa sambil memberikan apresiasi agar siswa merasa senang, guru menyampaikan tujuan pembelajaran dan pokok-pokok materi yang akan dipelajari; 2) Kegiatan Inti. Guru menanyakan setiap siswa tentang apa yang diketahui pada materi pelajaran sekarang, siswa di jadikan 5 kelompok, dan ditugaskan untuk menjawab pertanyaan dari guru dengan cara diskusi kelompok, siswa menyampaikan hasil diskusi dari pertanyaan guru dan siswa yang lain mendengarkan serta memberikan pertanyaan yang berkaitan dengan pertanyaan guru tersebut, dengan mengacu pada jawaban siswa, melalui tanya jawab, guru dan siswa membahas cara penyelesaian masalah yang tepat, guru mengadakan refleksi dengan menanyakan ulang dari hasil diskusi kelompok hingga pembelajaran berakhir; 3) Kegiatan Akhir. Guru menjelaskan ulang pembelajaran dengan singkat, guru memberikan apresiasi sebagai penutup pembelajaran, guru menutup pembelajaran dengan ucapan hamdalah. ${ }^{13}$

\section{Learning Community}

Pengembangan Model Pembelajaran Contextual Teaching And Learning melalui Learning Community untuk Meningkatkan Kreativitas Siswa pada Mata Pelajaran Tematik Kelas V di MIS Tarbiyatul Mubtadiin Labruk Lor Lumajang. Sebagaimana hasil observasi peneliti, bahwa penerapan model pembelajaran contextual teaching and learning melalui learning community untuk meningkatkan kreativitas siswa pada mata pelajaran tematik kelas V di MIS Tarbiyatul Mubtadiin Labruk Lor Lumajang adalah dilakukan dengan beberapa langkah, yaitu: 1) Kegiatan Awal: a) Guru menyiapkan peserta didik secara psikis dan fisik untuk mengikuti proses pembelajaran; b) Apersepsi, sebagai penggalian pengetahuan awal siswa terhadap materi yang akan diajarkan; c) Guru menyampaikan tujuan pembelajaran dan pokok-pokok materi yang akan

\footnotetext{
${ }^{13}$ Aini Ifadah, wawancara, , MIS Tarbiyatul Mubtadiin Labruk Lor Lumajang, 22 Maret 2018
} 
dipelajari; d) Penjelasan tentang pembagian kelompok dan cara belajar: 1) Kegiatan Inti: a) Siswa bekerja dalam kelompok menyelesaikan permasalahan yang diajukan guru. Guru berkeliling untuk umelihat keseriusan siswa; b) Siswa diminta untuk mempresentasikan hasil penyelesaian dan alasan atas jawaban permasalahan yang diajukan guru; c) Siswa dalam kelompok menyelesaikan lembar kerja (LKS) yang diajukan guru. Guru berkeliling untuk mengamati, memotivasi, dan memfasilitasi kerja sama; d) Siswa diminta untuk memprentasikan hasil kerja kelompok dan kelompok yang lain menanggapi hasil kerja kelompok yang mendapat tugas; e) Dengan mengacu pada jawaban siswa, melalui tanya jawab, guru dan siswa membahas cara penyelesaian masalah yang tepat; f) Guru mengadakan refleksi dengan menanyakan kepada siswa tentang hal-hal yang dirasakan siswa, materi yang belum dipahami dengan baik, kesan dan pesan selama mengikuti pembelajaran; 3) Kegiatan Akhir: a) Guru dan siswa membuat kesimpulan; b) Siswa mengerjakan lembar tugas LKS; c) Siswa menukarkan lembar tugas satu dengan yang lain, kemudian, guru bersama siswa membahas penyelesaian lembar tugas dan sekaligus dapat memberi nilai pada lembar tugas sesuai kesepakatan yang telah diambil (ini dapat dilakukan apabila waktu masih tersedia). ${ }^{14}$ Berdasarkan hasil observasi tersebut senada dengan yang disampaikan oleh Rofi'ati selaku guru kelas $\mathrm{V}$, dalam wawancaranya menyampaikan bahwa: "Adapun penerapan metode CTL melalui Learning Community adalah bertujuan agar hasil pembelajaran siswa diperoleh dari kerjasama dengan dengan siswa yang lain. Hasil belajar itu diperoleh dari diskusi dan sharing antarsiswa, antar kelompok, dan antar yang sudah tahu dengan yang belum tahu tentang suatu materi. Metode ini diterapkan dengan mengelompokkan siswa yang terikat dalam

\footnotetext{
${ }^{14}$ Observasi, MIS Tarbiyatul Mubtadiin Labruk Lor Lumajang, 12 Maret 2018
} 
kegiatan belajar, bekerjasama dengan siswa lebih baik daripada belajar sendiri dan saling bertukar pengalaman serta berbagi ide". ${ }^{15}$

Penerapan model pembelajaran contextual teaching and learning melalui learning community untuk meningkatkan kreativitas siswa pada mata pelajaran tematik kelas V di MIS Tarbiyatul Mubtadiin Labruk Lor Lumajang dilakukan dengan beberapa tahap, yaitu: 1) Kegiatan Awal. Guru menyiapkan peserta didik secara psikis dan fisik untuk mengikuti proses pembelajaran, kemudian apersepsi, sebagai penggalian pengetahuan awal siswa terhadap materi yang akan diajarkan, selanjutnya guru menyampaikan tujuan pembelajaran dan pokok-pokok materi yang akan dipelajari dan menjelaskan tentang pembagian kelompok dan cara belajar; 2) Kegiatan Inti. Siswa bekerja dalam kelompok menyelesaikan permasalahan yang diajukan guru. Guru berkeliling untuk melihat keseriusan siswa, siswa diminta untuk mempresentasikan hasil penyelesaian dan alasan atas jawaban permasalahan yang diajukan guru, siswa dalam kelompok menyelesaikan lembar kerja siswa (LKS) yang diajukan guru. Guru berkeliling untuk mengamati, memotivasi, dan memfasilitasi kerja sama dan siswa diminta untuk memprentasikan hasil kerja kelompok dan kelompok yang lain menanggapi hasil kerja kelompok yang mendapat tugas, kemudian dengan mengacu pada jawaban siswa, melalui tanya jawab, guru dan siswa membahas cara penyelesaian masalah yang tepat. Selanjutnya guru mengadakan refleksi dengan menanyakan kepada siswa tentang hal-hal yang dirasakan siswa, materi yang belum dipahami dengan baik, kesan dan pesan selama mengikuti pembelajaran; 3) Kegiatan Akhir. Guru dan siswa membuat kesimpulan kemudian siswa mengerjakan lembar tugas LKS dan siswa menukarkan lembar tugas satu dengan yang lain, kemudian, guru bersama siswa membahas penyelesaian lembar tugas dan

\footnotetext{
${ }^{15}$ Rofi'ati, wawancara, , MIS Tarbiyatul Mubtadiin Labruk Lor Lumajang, 12 Maret 2018
} 
sekaligus dapat memberi nilai pada lembar tugas sesuai kesepakatan yang telah diambil. ${ }^{16}$

\section{Penutup}

MIS Tarbiyatul Mubtadiin Labruk Lor Lumajang dalam meningkatkan keaktifan siswa kelas $\mathrm{V}$ dalam proses pembelajaran menerapkan model pembelajaran contextual teaching and tearning melalui constructivisme, questioning, dan melalui learning community.

\section{Daftar Pustaka}

Dimyati dan Mudjiono, 2009, Belajar dan Pembelajaran, Jakarta: PT Rineka Cipta.

Dokumentasi, MIS Tarbiyatul Mubtadiin Labruk Lor Lumajang Tahun Pelajaran 2017/2018.

Gunawan Adi W, 2002, Genius Learning Strategy, Jakarta: PT. Gramedia Pustaka Utama.

Ifadah Aini 2018, wawancara, MIS Tarbiyatul Mubtadiin Labruk Lor Lumajang.

Ismail, 2008, Strategi Pembelajaran Agama Islam Berbasis PAIKEM, Semarang. Rasail Media Group.

Muhibbin Syah, 2009, Psikologi Belajar, Jakarta: PT Raja Grafindo Persada.

Observasi, 2018, MIS Tarbiyatul Mubtadiin Labruk Lor Lumajang.

Putri Rachellia, 2018, wawancara, MIS Tarbiyatul Mubtadiin Labruk Lor Lumajang.

Ramayulis, 2005, Metodologi Pendidikan Agama Islam, Jakarta: Kalam Mulia.

Rofi'ati, wawancara, MIS Tarbiyatul Mubtadiin Labruk Lor Lumajang.

Sanjaya Wina, 2008, Strategi Pembelajaran: Berorientasi Standar Proses Pendidika, Jakarta: Kencana.

\footnotetext{
${ }^{16}$ Rofi'ati, wawancara, MIS Tarbiyatul Mubtadiin Labruk Lor Lumajang, 12 Maret 2018 